\title{
UMA AVALIAÇÃO DAS TOMADAS DE DECISÃO DE VALIGNANO DO PONTO DE VISTA DA SOCIEDADE JAPONESA ${ }^{1}$
}

\section{Shinzo Kawamura ${ }^{2}$}

\section{Introdução}

Qualquer pesquisador estudando a história da Missão Jesuíta no Japão dos séculos XVI e XVII irá reconhecer o fato de que o protagonista e figura chave desse período foi Alessandro Valignano (1539-1606). Valignano nasceu em família nobre de Chieti, uma cidade abastada no centro da península Italiana, localizada perto do Mar Adriático. Quando jovem ele se formou em direito civil na Universidade de Pádua, um centro da Renascença Italiana. Ao entrar na Companhia de Jesus, ele estudou sob os cuidados de acadêmicos de peso da época, como Christopher Clavius, no Colégio Romano (Collegio Romano). Talvez seja possível encarar Valignano como um extraordinário intelectual da Renascença. Sua chegada ao Japão em 1579 é um evento histórico definitivo, através do qual o encontro da Cultura da Renascença Européia com a sociedade e religião Tradicional Japonesa tornou-se uma realidade. Valignano deixou o Japão rumo a Macau em 1603, e antes desta data ele investigou a missão japonesa como um todo ao curso de três períodos, especificamente 1579-82, 1590-92, e 15981603. Todos os seus valiosos encontros aprofundaram sua compreensão da cultura, sociedade e religião do Japão, e eventualmente resultou na criação de uma política única para a missão, algo que jamais tinha sido visto em nenhuma outra parte do globo.

Nesse artigo, eu gostaria de levantar algumas questões com relação às suas tomadas de decisão na missão Japonesa. As decisões tomadas por Valignano foram supostamente bem recebidas quase unanimemente por seus colegas jesuítas, embora

\footnotetext{
${ }^{1}$ Tradução Angélica Alencar.

${ }^{2}$ Professor do departamento de História, Humanidades, da Universidade Sophia em Tóquio. Contato: Universidade Federal de Pernambuco, CFCH, Dept. de História, 11. andar, Av. da Arquitetura, s/n, CEP: 50740-550, Cidade Universitária, Recife-PE, Brasil. E-mail: cadernosdehistoriaufpe@ gmail.com.
} 
alguns superiores como Francisco Cabral e Pedro Ramon sejam conhecidos por terem criticado e discordado delas. No entanto, isso seria ver o caso do ponto de vista Jesuíta e Cristão, mas não podemos negar a possibilidade de outras interpretações e avaliações com relação ao assunto. Se a situação for vista do ponto de vista local, no caso, o Japão, um cenário diferente aparece diante dos nossos olhos. Em particular, creio que é importante avaliar as decisões de Valignano no contexto do período sengoku, ou a Era dos Estados em Guerra no Japão, e ao fazê-lo, a reação de Hideyoshi - o indivíduo que planejou um novo e unificado Japão - aumenta de importância.

\section{Contribuição do Plano Missionário de Valignano no Japão: O ponto de vista da Igreja}

(1) Promoção do "Método de Acomodação"

Valignano não apenas repetiu os métodos dos missionários anteriores, que foram seus predecessores, sem questionamento. Ele enfatizou o valor de entender as características locais nas situações enfrentadas pelos jesuítas, e descobriu uma maneira de acomodação ou adaptação, para estabelecer relações harmoniosas com a nobreza japonesa, governadores e líderes religiosos, sem mencionar a população comum.

\section{(2) Esforços e Arrecadação de Fundos}

Valignano era um indivíduo com os pés no chão. Ele deu bastante atenção à forma de obter fundos para a missão japonesa, e para esse propósito deu permissão aos Jesuítas para obter dinheiro com o comércio de seda crua entre o Japão e a China através das naus portuguesas. Aqui os jesuítas realmente assumiram o papel de intermediários.

\section{(3) Forte Consenso Entre Jesuítas}

Ele frequentemente realizou conferências (Nagasaki em 1581) e encontros para manter um consenso forte entre os missionários jesuítas no Japão.

\section{(4) Sistema das Cartas Anuais}

Valignano começou o Sistema das Cartas Anuais em 1581. Antes disso não havia regra obrigando as pessoas a escreverem relatos, por isso os missionários tinham a 
tendência de escrever apenas sobre os sucessos das missões. Como resultado, os jesuítas no quartel-general na Índia e na Europa frequentemente confundiram a situação, acreditando que a missão japonesa estava sempre indo bem. Dando-se conta dos deméritos dessa situação, Valignano transformou a escrita de relatos em regra rígida. Todos os relatos dos missionários tinham que ser submetidos anualmente ao superior geral da missão, que - após checar o conteúdo - o editava e resumia. Assim nasceu o sistema da carta anual.

(5) Estabelecimento de Instituições para a Formação Clerical (padres)

Valignano estabeleceu seminários e colégios. Ele também procurou sincronizar o sistema educacional europeu com a educação tradicional japonesa baseada em textos chineses clássicos.

(6) A Igreja Japonesa como membro da Igreja Universal

Valignano particularmente enfatizou a importância de se ensinar Latim aos seminaristas japoneses porque ele acreditava que o Latim era a língua Universal da Igreja. Com o conhecimento do idioma, a Igreja Japonesa poderia se comunicar não apenas como outras Igrejas, mas também com a Igreja Universal.

(7) Planejamento da Embaixada Tenshō (1582-90)

Valignano tomou vantagem da Embaixada Tenshō, que consistiu em quatro meninos advindos de famílias de Senhores Cristãos Japoneses. Os europeus que viram esses jovens ficaram profundamente impressionados e isso deu uma ideia de sucesso à missão japonesa. Da mesma forma, Valignano esperava que os meninos japoneses que viram a Europa Cristã, ao retornarem ao Japão, se tornassem eloquentes testemunhas para a população japonesa.

\section{(8) Introdução da prensa móvel européia}

O objetivo maior ao introduzir a prensa foi iniciar propaganda panfletista no Japão. Dessa forma, mais de 100 publicações, incluindo as conhecidas "kirishitan ban", bem como escritos jesuítas como a "Doctrina Kirishitan" e "Manuale ad Sacramenta", foram impressos. 


\section{Avaliação da Política da Missão de Valignano do Ponto de Vista da Sociedade Japonesa}

Mudança de ponto de vista: O ponto de vista dos Jesuítas versus o dos Japoneses que tomavam decisões

Ninguém duvida da importância da contribuição de Valignano para a missão japonesa. Entretanto, por outro lado, como avaliar sua forma de proceder no contexto da história japonesa? Eu também gostaria de avaliar sua tomada de decisão vista através dos olhos japoneses, e ver como sua tal, para a Igreja, pode ser vista no contexto da História Japonesa.

O suposto Século Cristão Japonês terminou com a política anti-cristã dos Tokugawa. A totalidade da cristandade japonesa desapareceu da cena histórica. Os esforços de Valignano, sem dúvida, ajudaram a frutificar a Igreja Cristã do Japão, mas o resultado final foi que a missão japonesa terminou em fracasso. Desnecessário dizer que, no entanto, não se pode colocar toda a culpa em Valignano; mas ao isolar os fatores mais cruciais por trás desse fracasso da missão, posso evitar o sentimento de que sua tomada de decisão foi um dos principais fatores que levaram à sua ruína. Colocando de forma simples, foi sua decisão de aceitar o porto de Nagasaki como um território eclesiástico o que trouxe o infeliz fim ao Século Cristão Japonês.

As políticas negativas do governo japonês com relação à cristandade começaram com o Édito de Expulsão dos Bateren [padres] de Toyotomi Hideyoshi em Junho de 1587. Analisando o texto do édito, a diferença entre o que os jesuítas pretendiam e o que o governador japonês desejava é bem clara. Como afirmei, o erro crucial foi a aceitação do domínio jesuíta de Nagasaki, e foi Valignano quem possibilitou isso. Ainda que o édito de expulsão de Hideyoshi não se refira diretamente ao domínio jesuíta, é certo que Hideyoshi, que procurava incluir todas as áreas [do Japão] sob seu domínio, desgostou da possessão jesuíta de Nagasaki, o que provou uma ameaça séria e o mais insuperável obstáculo ao seu maior objetivo de unificar o país. 


\section{O Édito de Expulsão dos Bateren (Julho de 1587)}

Até agora houve muitos debates sobre o édito de Hideyoshi, e opiniões diferem com relação ao propósito do mesmo, para quem ele foi ultimamente endereçado e assim por diante. De fato, o chamado "Édito de Expulsão dos Bateren” tem duas variações do texto original. Uma consiste de decretos restringindo a prática do cristianismo (onze vezes), e o outro são decretos expulsando os missionários do Japão (cinco vezes). O primeiro (oboe 覚, ou nota) foi publicado em 23 de Julho de 1587 (18 de Junho da Era Tensho), e o segundo (sadamae 定, ou ordem) foi publicado no dia 24 de Julho (19 de Junho da Era Tensho) do mesmo ano.

1. O fato de se tornar seguidor dos Bateren deve ser uma escolha livre da pessoa em questão.

2. É insensato acima de qualquer palavra, e revoltante, que quem recebeu como feudo províncias, distritos e estados forcem os camponeses registrados em templos budistas e outros inquilinos, contra sua vontade, a se juntarem às fileiras dos seguidores dos Bateren.

3. Províncias e estipêndios são dados em feudo com estabilidade limitada ao titular. O receptor pode mudar, mas os camponeses não mudam. No caso de demandas insensatas exercidas em qualquer ponto, o recipiente será retido. Aja de acordo.

4. Pessoas que retêm acima de 200 chō ou duzentos e trezentos kan poderão se tornar seguidores dos Bateren ao obterem permissão oficial, concordando com a vontade do senhor do Tenka.

5. Pessoas obtendo estipêndios abaixo do mencionado anteriormente: na questão da escolha entre as Oito Seitas e as Nove Seitas, o cabeça da família deve decidir como bem entender, apenas para si.

6. Chamou a atenção do senhor do Tenka que os seguidores dos Bateren são muito dados a conjuras e elementos exteriores, mais ainda que os da Seita Ikkō. A Seita Ikkō estabeleceu precintos dos templos nas províncias e distritos e não pagou taxas anuais aos recipientes inquilinos. Ainda mais, fizeram toda a província de Kaga em seguidores Ikkō, expulsaram Togashi, o senhor da província, entregaram 
estipêndios aos monges da Seita Ikkō e, acima de tudo, ainda tomaram Echizen. Dizer que esse fato foi nocivo ao Tenka é uma verdade que não se pode negar.

7. Os monges seguidores da Ikkō construíram templos em todas as baías e enseadas. Embora tenham sido perdoados, eles não mais regulam as questões nos precintos dos seus templos da mesma maneira que antes.

8. Aqueles daimyō que estejam de posse de províncias e distritos ou de seguidores são ainda mais indesejáveis que o estabelecimento de precintos de templos dos seguidores Honganji, e estão sujeitos a prejudicar o Tenka. Esses indivíduos sem reserva estarão sujeitos a punição.

9. Os seguidores dos Bateren, de escolha livre, contanto que sejam das classes baixas, não deverão ser molestados, sendo esta uma questão das Oito Seitas ou Nove Seitas.

10. A venda de Japoneses à China, Bárbaros do Sul e Coréia é ultrajante. Adendo: é proibido o comércio de seres humanos no Japão.

11. Comércio e assassinato de gado e cavalos para serem consumidos como comida também será considerado crime.

Os ítens acima devem ser mantidos em estrita proibição. Qualquer transgressor deverá ser imediatamente punido de maneira severa. Tenshō 15/6/18 [23 de Julho de 1587] Selo Vermelho (Hideyoshi) (Traduzido para o Inglês por George Elison, Deus Destroyed, pp. 117-118)

\section{Semelhanças entre o Cristianismo e a Seita Honganji (Ikkō)}

Eu sou da opinião de que o espírito mais importante do édito pode ser encontrado no Oboe, ou na Nota. Gostaria de focar em duas frases.

(1) "Veio à atenção do senhor do Tenka que os seguidores dos Bateren são ainda mais dados a conjurações com elementos exteriores que a Seita Honganji."

(2) "A Seita Honganji estabeleceu precintos de templos nas províncias e distritos. E não pagam anualmente as devidas taxas. Além do mais, eles transformaram toda a 
província de Kaga em seguidores da [Seita] Ikkō [...] entregaram os estipêndios aos monges da Seita Ikkō."

Nessas frases, Hideyoshi claramente mostra a similaridade entre os cristãos e os seguidores Honganji, ou os que crêem na seita Jōdo Shinshū (Terra Pura). Seita Honganji é o outro nome da mesma.

Historiadores recentes expressaram suas opiniões sobre as semelhanças entre as duas religiões. Por exemplo, George Elison, autor de Deus Destroyed, uma monografia meticulosa sobre a história dos cristãos japoneses, aponta a importância da questão.

O principal ponto da comparação de Hideyoshi foi a similaridade implícita da soteriologia, e as implicações sociais da Shinshū e do cristianismo [...]. Para ele, ambas as religiões dominavam a mente dos crentes a partir de uma abordagem sola fide. Os aderentes da Ikkō encontraram suas justificativas na compaixão sem limites de Amida, os cristãos na piedade sem limites de Deus; Fé era a Verdade. A consciência religiosa estendia-se à motivação política e organizacional. [...] Seria um tópico interessante de pesquisa mais profunda para investigar se a analogia de Hideyoshi tinha base detalhada de verdade ou não: estaria a atividade comunal dos cristãos verdadeiramente em dívida, como imitação da estrutura ou na utilização dos preceitos, para com as técnicas da Ikkō?

A questão da intercessão histórica entre as duas religiões é muito importante, mas não é algo sem complicação. A bem da verdade, nenhum trabalho monográfico dedicado à intercessão histórica entre as duas religiões jamais foi publicado. Eu acredito que Hideyoshi foi a primeira figura histórica a comentar as naturezas similares de ambas. Antes de publicar o édito, Hideyoshi se encontrou com um missionário jesuíta em Osaka e comunicou-lhe questões similares ao conteúdo do mesmo.

\section{Semelhanças organizacionais entre o cristianismo e a seita Terra Pura}

No meu livro recente sobre as Organizações Laicas Cristãs, foquei no aspecto estrutural das organizações religiosas, e apontei a similaridade entre o sistema das organizações laicas cristãs e as organizações de crentes da Jōdo Shinshū (浄土真宗). No século dezesseis, comunidades religiosas no Japão tinham muitos elementos em comum. Por exemplo, a forma como as confrarias européias foram introduzidas no 
Japão quando os cristãos japoneses estabeleceram seus próprias comunidades socioreligiosas. Mesmo sem a liderança de padres, a população laica pôde manter suas atividades comunais. As organizações consistiam em líderes laicos locais, capelas nas residências, encontros para orar, e ajuda mútua entre os habitantes de vilas distintas. Esse sistema foi facilmente adotado pelos japoneses, porque o modelo similar de uma organização religiosa já existia na forma do sistema de dōjō da Jōdo Shinshū. Os crentes da Shinshū tinham congregações regulares chamadas kō (講) [associação] que acontecia no dōjō (道場) [salão usado para artes marciais], ou local de encontro, e tinham o cuidado de ajudarem os membros do grupo mutuamente. Nesse sentido, a associação da seita Shinshū Honganji poderia ser comparada à confraria cristã. Dōjō e kō eram os elementos básicos do Honganji Jinai (o precinto do templo). Os crentes da seita Jōdo Shinshū Honganji criaram uma área administrativa independente, e a autoridade e o poder dos lordes seculares (daimyō) não se manteve bem nessa área. Em verdade, o Jinai era motivo de desgosto para os senhores seculares. Igualmente, as organizações cristãs tinham a mesma potencialidade que a Shinshū Jinai possuía.

\section{A maior Jinai (寺内) ou precinto religioso no Japão: o domínio jesuíta de Nagasaki}

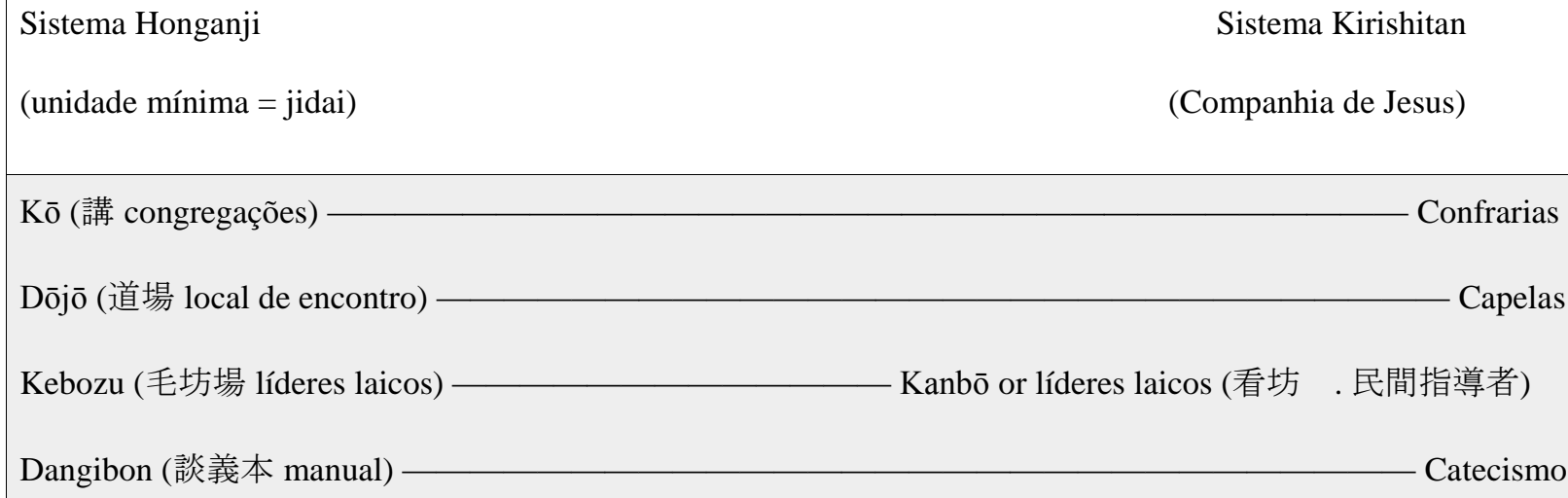

A jinai-cho (寺内町), ou cidade do precinto do templo, sempre levantou um grande problema e foi um obstáculo para os senhores seculares, que normalmente foram forçados a conduzir a desintegração do precinto do templo (jinai giri 寺内切). $\mathrm{Na}$ 
verdade, a desintegração da Jinai era sua tarefa mais imperativa. Em particular, Toyotomi Hideyoshi, o mais influente dos senhores seculares à época e potencial unificador do país, não permitiu nenhum grupo religioso de estabelecer áreas autônomas no seu território. Na verdade, Hideyoshi ativamente realizou a dissolução da Shinshū Jinai em todos os locais. Nesse contexto temos que considerar sua política de separação da religião e da política, bem como a dos soldados e dos camponeses.

A mesma lógica poderia ser aplicada quando Hideyoshi veio a conhecer a existência do domínio jesuíta de Nagasaki. Estou inclinado a acreditar que Hideyoshi encarou o domínio jesuíta de Nagasaki como a maior "Jinai" (precinto da Igreja). Um precinto cristão como Nagasaki era maior e mais forte que todos os outros precintos no Japão porque a Sociedade de Jesus tinha ligações com poderes estrangeiros como Espanha e Portugal. A frase do édito dos Bateren, "ainda mais dados a conjurações com elementos externos que a Seita Ikkō" provavelmente se refere à situação de Nagasaki.

\section{A transferência de Nagasaki: de Ōmura para a Companhia de Jesus}

Ōmura Sumitada, o senhor cristão, assinou um documento e transferiu para os padres da Companhia a soberania do porto de Nagasaki e do pequeno porto vizinho de Mogi. A data é 9 de Junho de 1580 (o vigésimo quarto dia da quarta lua do ano oito de Tensho).

Abaixo está, em linhas gerais, a doação, como presente, das duas localidades de Mongui e Nagasaqi feita por Dom Bartholomeu, senhor de Ōmura.

Dom Bartholomeu, senhor de Ōmura, e seu filho Sancho. Em vista da minha dívida para com os padres da Sociedade, eu dou livremente como presente em perpetuidade a cidade de Nagasaki com toda a propriedade existente e terreno contido no território. Eu, assim, transfiro a possessão para eles de agora em diante. Os ditos padres da Sociedade podem apontar qualquer pessoa de sua escolha como capitão do lugar mencionado ou podem dispensá-lo do ofício de acordo com seu discernimento. Eu dou à pessoa escolhida por eles o poder sobre vida e morte, e tal autoridade de administrar justiça como será necessário para o bom governo e para a punição daqueles que violam as leis existentes.

Da mesma forma, dou e dôo a eles o que o navio português está acostumado a pagar enquanto permanece no dito porto; eu reservo a 
mim o costumeiro faturamento em respeito àquele navio e todos os outros que entrarem no mencionado porto. Isto eu irei arrecadar entre meus próprios oficiais, que não devem interferir de nenhuma forma com o que concerne à administração da justiça ou do governo do local mencionado.

Da mesma forma, eu dou aos padres em perpetuidade o distrito de Mogui[sic] com toda a propriedade existente e terreno pertencente a esse. Em testemunho de que os termos desse presente jamais serão revogados, mas que devem ter validade perpétua, eu escrevi esse documento, assinado por mim e por meu filho Sancho no vinte e quatro do quarto mês do oitavo ano [da era] Tenshō [9 de Junho de 1580]. Dom Bartolomeu Dom Sancho. ${ }^{3}$

O começo do porto de Nagasaki data de aproximadamente 1570. Antes de 1570, havia portos importantes nas áreas de Ōmura e Shimabara, como Yokoseura, Fukuda, Shiki e Kuchinotsu. Nagasaki tinha se desenvolvido rapidamente durante os anos de 1570, devido ao fato de que foi um bom local de âncora e porto para a nau, o grande navio de Portugal. O total da população da cidade chegou a aproximadamente 30,000 e J.F. Schütte, Valignano's Mission Principles for Japan, vol. 1. part I. p. 328. English tras. by John J. Coyne.devidas aos navios, que era cerca de três mil ducados, e isso tornou-se a principal fonte de renda do seu território. Daí o porto de Nagasaki ter sido indispensável para sua administração. No entanto, ao mesmo tempo, ele encarou o recuo da guerra com Ryūzōji Takanobu, o daimyō das regiões de Isahaya e Saga. Sumitada teve que encontrar suporte forte para poder proteger Nagasaki, e Valignano também teve esperanças de que se Nagasaki pertencesse à Igreja, os cristãos poderiam sempre usá-la como um local de refúgio em tempos de perigo e tumulto. Aqui, os interesses de Valignano e Ōmura Sumitada se harmonizaram.

Em 1580, Valignano realizou uma conferência em Nagasaki, e missionários jesuítas discutiram vinte e um pontos na agenda. Eles discutiram acaloradamente sobre questões importantes como o método de adaptação, a formação de padres e assim por diante. O ponto número 14 da agenda diz respeito a possessão de Nagasaki, especificamente se era razoável para a Sociedade de Jesus no Japão aceitar os portos de Nagasaki e Mogi como seu território. Os outros vinte pontos estavam relacionados à questão da acomodação, e apenas quatorze na agenda diziam respeito a outras questões. Os participantes foram unanimemente em favor da aceitação da oferta de Ōmura

\footnotetext{
${ }^{3}$ SCHÜTTE, J.F.. Valignano's Mission Principles for Japan, vol. 1. part I. p. 328. English tras. by John J. Coyne.
} 
Sumitada e de seu filho, e Valignano também concordou com esta decisão. É provável que Valignano e os outros Jesuítas não estivessem cientes da seriedade da natureza da transferencia quando vista no contexto social japonês. O domínio jesuíta de Nagasaki tinha a mesma função e natureza que a Shinshū Jinai tinha, por isso parecia uma grande "Jinai".

Tendo uma visão nacional da situação, parece-me que a transferência de Nagasaki para a Sociedade de Jesus teve uma significação social importante que pesquisadores jamais mencionaram até o momento. Valignano aceitou não apenas o porto de Nagasaki, mas também o porto de Mogi (茂木). O principal ponto é o local de Mogi. Acho que o significado de Mogi foi maior que o de Nagasaki. Por favor, dê uma olhada no mapa [Mapa 1].

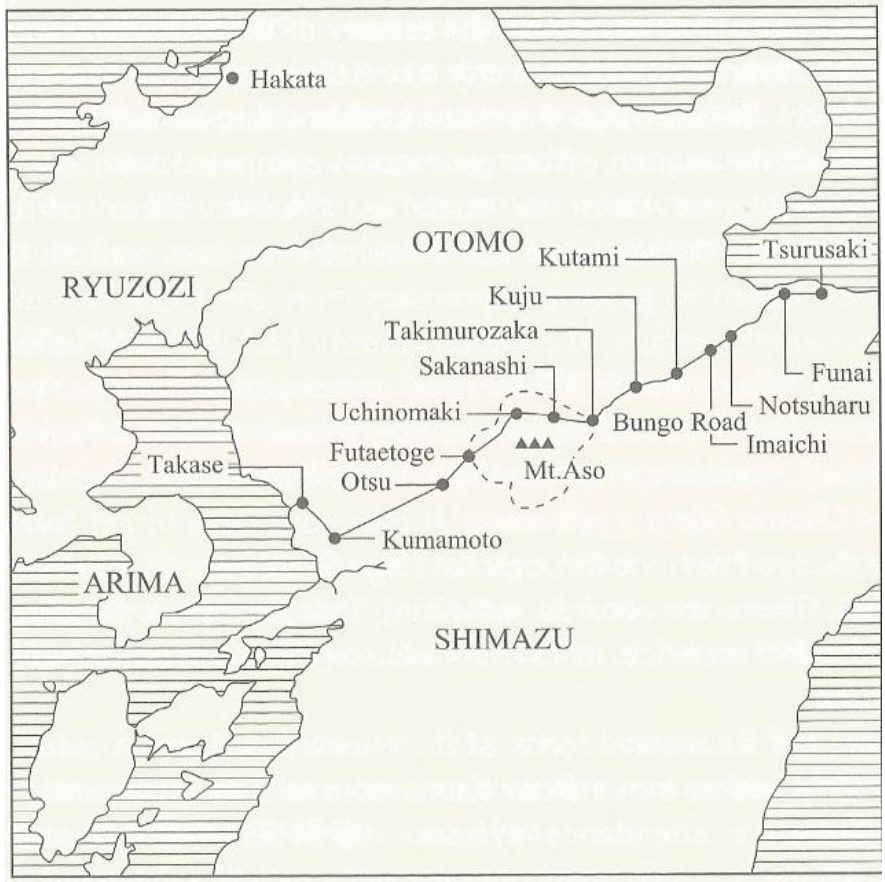

Nagasaki, Mogi e a Península de Shimabara

Mapa da estrada de Bungo (de Takase a Funai) 
Hoje Mogi é uma pequena cidade portuária de frente para a baía Tachibana, próximo da península de Shimabara. Com fotografia de satélite podemos ver melhor a

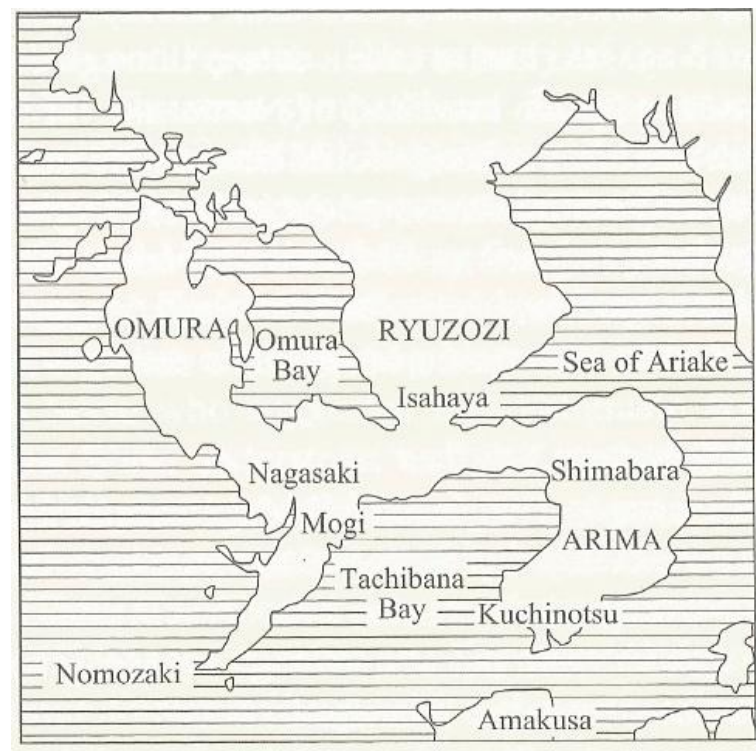

localização e a situação. Quando os cristãos de Nagasaki desejavam ir à península de Shimabara, onde todos os habitantes foram batizados após o senhor Arima Harunobu se tornar cristão, eles tinham que ir através da região de Isahaya. Por volta de 1580 , no entanto, essa área foi ocupada por Ryūzōji Takanobu, um senhor anti-cristão e inimigo de Ōmura Sumitada. Daí o povo de Nagasaki ter tido que fazer um desvio através do canal da península de Nagasaki, perto do promontório de Nomozaki (野母崎). No entanto, na verdade, tanto à época quanto nos dias atuais, ninguém gostaria de fazer tamanho e difícil desvio. A importância estratégica do porto de Mogi pode ser melhor compreendida quando vista desta perspectiva. Se os jesuítas fizeram de Mogi seu território, eles automaticamente obtiveram um desvio entre Nagasaki e a península de Shimabara, e por essa razão Mogi teve uma importância estratégica.

\section{O papel do "Cinturão Kirishitan"}

O significado de possuir Nagasaki e Mogi não estava limitado à questão relativa ao território de Ōmura. Através dessa possessão era possível para os jesuítas aumentar ainda mais as fileiras da sua missão. As áreas cristãs de Nagasaki até o distrito de Miyako estavam interligadas como através de uma longa linha, e por conveniência eu a nomeei o "Cinturão Kirishitan". 
A rota do mar entre a península de Shimabara e a província de Higo é fácil de ser cruzada porque o mar Ariake (cujo nome é Shiranui kai 不知火海) é um mar interno, e a superfície é sempre calma. Navios de Shimabara normalmente entram no porto de Takase (高瀬), um dos melhores portos na província de Higo e uma cidade livre próxima ao estuário do rio Kikuchi (菊池川). Esse pequeno porto se desenvolveu como uma cidade livre igual a Sakai durante a segunda metade do século dezesseis. Na província de Higo daquela época, muitos senhores locais de influência (Kunishu 国衆 ou homens das províncias) competiam uns com os outros. Ao mesmo tempo, grandes daimyō como Ōtomo Sōrin da província de Bungo, Shimazu Yoshihisa da província de Satsuma, e Ryūzōji da província de Saga focaram em ganhar supremacia sobre a província de Higo. Na verdade, durante o século dezesseis, a família Ōtomo tinha a maior influência na província de Higo. O porto de Takase foi desenvolvido sob a hegemonia de Ōtomo Sōrin, o qual recebeu negociantes e mercadores, bem como missionários jesuítas, nessa cidade. Quase todas as principais áreas cristãs de Kyushu ficaram sob o domínio da influência de Ōtomo Sōrin. Levava quatro dias para ir de Takase para Funai na província de Bungo através da estrada de Higo (cujo nome na época era Bungo). Há registros indicando que os missionários jesuítas frequentemente usaram essa estrada. Por exemplo, em 1573, Francisco Cabral a usou na sua viagem de inspeção a Miyako.

Adicionalmente, os senhores sucessores do domínio de Hosokawa fizeram uso dessa rota quando eles tiveram que mover de Kumamoto para Edo de acordo com ordem do sistema de presença alternativa (参勤交代の道 Sankin kōtai no michi).

Além de Higo ou da estrada de Bungo, o Cinturão Kirishitan se estendia para as ilhas do mar interno de Seto (瀬戸内海 Setonaikai) e chegava a Sakai e Miyako. No meio do Setonaikai, havia muitas ilhas geridas por Suigun (水軍), senhores de guerra do mar interno. Eles fizeram contrato com os mercadores de Sakai, que através do Suigun garantiam navegação segura através de suas águas entre Sakai e Kyushu. A maioria dos mercadores de Sakai eram cristãos, ou ao menos simpatizantes dos cristãos. Em outras palavras, o "Cinturão Kirishitan" foi a rota que conectou Nagasaki e o distrito de 
Miyako. Esse "Cinturão Kirishitan" era muito importante para os cristãos e o domínio jesuíta de Nagasaki e Mogi foram a chave para a sua criação. Sem Mogi, o Cinturão Kirishitan não faria sentido. Valignano vislumbrou a verdadeira importância de adquirir Nagasaki e Mogi? É muito provável que Ōtomo Sōrin tenha sugerido a Valignano aceitar Nagasaki e Mogi. Sabe-se que Sōrin compreendia bem o potencial estratégico de Nagasaki e Mogi, mas Valignano também? Como não tenho ainda resposta para esta questão, preciso continuar minha pesquisa na área. No entanto, podemos ao menos afirmar isso: havia outra pessoa que entendia a importância do domínio jesuíta de Nagasaki, e esta pessoa era Toyotomi Hideyoshi. Hideyoshi viu refletido no domínio jesuíta de Nagasaki um caráter idêntico ao do "Jinai”.

\section{Conclusão}

Valignano se esforçou para procurar uma forma dos cristão sobreviverem durante o período Sengoku ou o período dos estados em guerra do Japão. Foi apenas com esse propósito que ele vislumbrou o "método de acomodação" e aceitou o conceito do domínio de Nagasaki e Mogi. Nagasaki era um território dos sonhos para os cristãos. Do ponto de vista da igreja e dos jesuítas, era o ideal. Por outro lado, no entanto, para os unificadores dos estados competidores, Nagasaki e o Cinturão Kirishitan eram como o Shinshū Jinai. Eles levantaram obstáculos e criaram inconveniências para unificadores como Oda Nobunaga e Toyotomi Hideyoshi.

\section{Referências bibliográficas}

ELISON, George. Deus Destroyed: The Image of Christianity in Early Modern Japan. Harvard University Asia Center, Reprint edition: 1988.

KAWAMURA, Shinzo. Kirishitan Shinto Soshiki no Tanjo To Henyo. Tokyo: Kyobunkan, 1993.

KUROZUMI, Makoto. "Kirishitan Kinsei To Kinsei Nihon: Hideyoshi Tensho 15 nen 6 gathus zuke Oboe wo megutte". In Sakai to Kokka Asia wo Kangaeru 4, eds. Yuzo Mizoguchi et al., Tokyo: The University of Tokyo Press: 1994 pp. 167-212.

MATSUDA, Kiichi. Ōmura Sumitada Den. Tokyo: Kyobunkan, 1978. 
SCHÜTTE, J. $\quad$ F. Introducio ad Historiam Societatis Jesu in Japonia 1549-

1650. Roma: Apud "Institutum Historicum Soc. Jesu", 1968.

Valignano's Mission Principles for Japan. Vol. 1. From His Appointment as Visitor until His first Departure from Japan (1573-1582). Part I: The Problem (1573-1580). St. Louis: The Institute of Jesuit Sources, 1985. 